\title{
Diet and the Risk of Head and Neck Cancer: A Pooled Analysis in the INHANCE Consortium
}

\author{
Shu-Chun Chuang ${ }^{1,2}$, Mazda Jenab ${ }^{2}$, Julia E. Heck ${ }^{3}$, Cristina Bosetti ${ }^{4}$, Renato Talamini ${ }^{5}$, \\ Keitaro Matsuo ${ }^{6}$, Xavier Castellsague ${ }^{7}$, Silvia Franceschi ${ }^{2}$, Rolando Herrero ${ }^{8}$, Deborah M. \\ Winn $^{9}$, Carlo La Vecchia ${ }^{4,10}$, Hal Morgenstern ${ }^{11}$, Zuo-Feng Zhang ${ }^{3}$, Fabio Levi ${ }^{12}$, Luigino \\ Dal Maso ${ }^{5}$, Karl Kelsey ${ }^{13}$, Michael D. McClean ${ }^{14}$, Thomas Vaughan ${ }^{15}$, Philip Lazarus ${ }^{16}$, \\ Joshua Muscat ${ }^{16}$, Heribert Ramroth ${ }^{17}$, Chu Chen ${ }^{15}$, Stephen M. Schwartz ${ }^{15}$, Jose Eluf- \\ Neto $^{18}$, Richard B. Hayes ${ }^{19}$, Mark Purdue ${ }^{9}$, Stefania Boccia ${ }^{20,21}$, Gabriella Cadoni ${ }^{22}$, David \\ Zaridze $^{23}$, Sergio Koifman ${ }^{24}$, Maria Paula Curado ${ }^{2}$, Wolfgang Ahrens ${ }^{25}$, Simone \\ Benhamou $^{26}$, Elena Matos ${ }^{27}$, Pagona Lagiou ${ }^{28}$, Neonilla Szeszenia-Dabrowska ${ }^{29}$, Andrew \\ F. Olshan ${ }^{30}$, Leticia Fernandez ${ }^{31}$, Ana Menezes ${ }^{32}$, Antonio Agudo ${ }^{33}$, Alexander W. Daudt ${ }^{34}$, \\ Franco Merletti ${ }^{35}$, Gary J. Macfarlane ${ }^{36}$, Kristina Kjaerheim ${ }^{37}$, Dana Mates ${ }^{38}$, Ivana \\ Holcatova $^{39}$, Stimson Schantz ${ }^{40}$, Guo-Pei $\mathbf{Y u}^{40}$, Lorenzo Simonato ${ }^{41}$, Hermann Brenner ${ }^{42}$, \\ Heiko Mueller ${ }^{42}$, David I. Conway ${ }^{43}$, Peter Thomson ${ }^{44}$, Eleonora Fabianova ${ }^{45}$, Ariana \\ Znaor $^{46}$, Peter Rudnai ${ }^{47}$, Claire M. Healy ${ }^{48}$, Gilles Ferro' ${ }^{2}$, Paul Brennan², Paolo \\ Boffetta $^{49,50}$, and Mia Hashibe ${ }^{2,51}$
}

${ }^{1}$ Imperial College London, London, UK ${ }^{2}$ International Agency for Research on Cancer (IARC), Lyon, France ${ }^{3}$ UCLA School of Public Health, Los Angeles, CA, USA ${ }^{4}$ Istituto di Ricerche Farmacologiche Mario Negri, Milan, Italy ${ }^{5}$ Aviano Cancer Centre, Aviano, Italy ${ }^{6}$ Aichi Cancer Center Research Institute, Nagoya, Japan ${ }^{7}$ Institut Català d'Oncologia, Barcelona, Spain ${ }^{8}$ Instituto de Investigación Epidemiológica, San José, Costa Rica ${ }^{9}$ National cancer institute, Bethesda, MA, USA ${ }^{10}$ Department of Occupational Health, University of Milan, Milan, Italy ${ }^{11}$ Department of Epidemiology and Environmental Health Sciences and Comprehensive Cancer Center, University of Michigan, Ann Arbor, MI, USA ${ }^{12}$ Institut Universitaire de Medecine Sociale et Preventive, Lausanne, Switzerland ${ }^{13}$ Brown University, Providence, RI, USA ${ }^{14}$ Boston University of Public Health, Boston, MA, USA ${ }^{15}$ Fred Hutchinson Cancer Research Center, Seattle, WA, USA ${ }^{16}$ Pen State College of Medicine, Philadelphia, USA ${ }^{17}$ University of Heidelberg, Heidelberg, Germany ${ }^{18}$ Departemento Medicina Preventiva, Universidade de Sao Paulo, Sao Paulo, Brazil ${ }^{19}$ New York University School of Medicine, NY, USA ${ }^{20}$ Institute of Hygiene, Università Cattolica del Sacro Cuore, Rome, Italy ${ }^{21}$ IRCCS San Raffaele Pisana, Rome, Italy ${ }^{22}$ Institute of Otorhinolaryngology, Catholic University of the Sacred Heart, Rome, Italy ${ }^{23}$ Cancer Research Center, Moscow, Russia ${ }^{24}$ Escola Nacional de Saude Publica, Rio de Janeiro, Brazil ${ }^{25}$ Bermen Institute for Prevention Research and Social Med, Bermen, Germany ${ }^{26}$ INSERM, Paris, France ${ }^{27}$ Institute of Oncology Angel $\mathrm{H}$. Roffo, Buenos Aires, Argentina ${ }^{28}$ Department of Hygiene, Epidemiology and Medical Statistics, School of Medicine, University of Athens, Athens, Greece ${ }^{29}$ Institute of Occupational Medicine, Lodz, Poland ${ }^{30}$ University of North Carolina, School of Public Health, Chapel Hill, NC, USA ${ }^{31}$ Institute of Oncology and Radiology, Havana, Cuba ${ }^{32}$ Faculdade de Medicina Universidade Federal de Pelotas, Pelotas, Brazil ${ }^{33}$ Catalan Institute of Oncology (ICO), Bellvitge Biomedical Research Institute (IDIBELL), Hospitalet de Llobregat, Barcelona,

Corresponding Author: Mia Hashibe, Ph.D., Division of Public Health, Department of Family \& Preventive Medicine, Huntsman Cancer Institute, University of Utah School of Medicine, 375 Chipeta Way, Suite A, Salt Lake City, UT, 84108, Phone: 801-587-3034, Fax: 801-587-3353, Mia.Hashibe@utah.edu.

Conflict of interest statement

None declare. 
Spain ${ }^{34}$ Hospital de Clinicas de Porto Allegre, Brazil ${ }^{35}$ Unit of Cancer Epidemiology, Turin, Italy ${ }^{36}$ School of Medicine and Dentistry, University of Aberdeen, Scotland, UK ${ }^{37}$ Cancer Registry of Norway, Oslo, Norway ${ }^{38}$ Institute of Public Health, Bucharest, Romania ${ }^{39}$ Institute of Hygiene and Epidemiology, Prague, Czech Republic ${ }^{40}$ Department of Surgery, Memorial Sloan Kettering Cancer Center, New York, USA ${ }^{41}$ Department of Environmental Medicine and Public Health, School of Medicine, University of Padova, Padova, Italy ${ }^{42}$ German Cancer Research Center, Heidelberg, Germany ${ }^{43}$ Dental School, College of Medical, Veterinary and Life Sciences, University of Glasgow, Glasgow, UK ${ }^{44}$ University of Newcastle Dental School, Newcastle, UK ${ }^{45}$ Specialized State Health Institute, Banská Bystrica, Slovakia ${ }^{46}$ Croatian National Cancer Registry, Zagreb, Croatia ${ }^{47}$ National Institute of Environmental Health, Budapest, Hungary ${ }^{48}$ Trinity College School of Dental Science, Dublin, Ireland ${ }^{49}$ The Tisch Cancer Institute, Mount Sinai School of Medicine, New York, NY, USA ${ }^{50}$ International Prevention Research Institute, Lyon, France ${ }^{51}$ University of Utah School of Medicine, Salt Lake City, UT, USA

\section{Abstract}

We investigated the association between diet and head and neck cancer (HNC) risk using data from the International Head and Neck Cancer Epidemiology (INHANCE) Consortium. The INHANCE pooled data included 22 case-control studies with 14,520 cases and 22,737 controls. Center-specific quartiles among the controls were used for food groups and frequencies per week were used for single food items. A dietary pattern score combining high fruit and vegetable intake and low red meat intake, was created. Odds ratios (OR) and 95\% confidence intervals (CI) for the dietary items on the risk of $\mathrm{HNC}$ were estimated with a two-stage random effects logistic regression model. An inverse association was observed for higher frequency intake of fruit ( $4^{\text {th }} \mathrm{vs.}$ $1^{\text {st }}$ quartile $\left.\mathrm{OR}=0.52,95 \% \mathrm{CI}=0.43-0.62, \mathrm{p}_{\text {trend }}<0.01\right)$ and vegetables $(\mathrm{OR}=0.66,95 \% \mathrm{CI}=0.49$ $\left.0.90, \mathrm{p}_{\text {trend }}=0.01\right)$. Intake of red meat $\left(\mathrm{OR}=1.40,95 \% \mathrm{CI}=1.13-1.74, \mathrm{p}_{\text {tren }}=0.13\right)$ and processed meat $\left(\mathrm{OR}=1.37,95 \% \mathrm{CI}=1.14-1.65, \mathrm{p}_{\text {trend }} \times 0.01\right)$ were positively associated with HNC risk. Higher dietary pattern scores, reflecting high fruit/vegetable and low red meat intake, were associated with reduced $\mathrm{HNC}$ risk (per score increment $\mathrm{OR}=0.90,95 \% \mathrm{CI}=0.84-0.97$ ).

\section{Keywords}

Diet; head and neck cancer; fruit and vegetable; red meat; processed meat

\section{Introduction}

Head and neck cancer (HNC), defined as cancers of the oral cavity, oropharynx, hypopharynx, and larynx, is the sixth most common cancer in the world, accounting for about 900,000 cases and 300,000 deaths in 2008 [1]. Tobacco smoking and alcohol drinking are the two most important risk factors for HNC [2], contributing to over 70\% of $\mathrm{HNC}$ cases [3]. Other important risk factors include passive smoking [4,5], human papillomavirus (HPV) infection [6], low body mass index (BMI) [7], and family history of cancer [8].

The inverse association of fruits and vegetables against HNC have been reported in many epidemiologic studies [9-16]. The recent World Cancer Research Fund (WCRF) report into diet and cancer summarized that the evidence was strong enough to support a probable causal relationship for a decreased HNC risk with non-starchy vegetables, fruits, and food containing carotenoids [17]. However, the evidence of the role of other food groups and the risk of HNC is inconsistent. Meat consumption was suggested to be a risk factor for several cancers [10,17-19], including HNC [9,15,20-22], but the association was not consistent $[11,23]$. Dairy products were positively associated with HNC in an American study [23], but 
the association was not observed in an Eastern European [11] or international study [24]. Even for vegetables, the evidence for cruciferous vegetables was not sufficient to make a conclusion in relation to HNC risks [11,12,17,23-31]. Moreover, residual confounding from smoking is still a major concern for the observed associations.

The International Head and Neck Cancer Epidemiology (INHANCE) Consortium is a collaboration of research groups leading large molecular epidemiology case-control studies of HNC (http://inhance.iarc.fr/). The consortium covers populations from Europe, North America, Latin America, India, Japan, and Australia. The large sample size enables us to explore the association between diet and HNC risk within never smokers to avoid the residual confounding from smoking. The geographic coverage helps us to explore the dietary effects on different background fruit and vegetable consumption levels. We took advantage of the data from the consortium to explore the associations between food groups and the risk of HNC.

\section{Methods}

The current analysis included 22 of the 26 studies in the consortium pooled data version 1.3. Compared with a previous publication [3], the current dataset included a US multicenter study [32], the MSKCC study [33], the Seattle-LEO study [34], the Western Europe study [9], the Saarland study [35], the Heidelberg study [36], and the Japan study [37]. Appendix 1 lists the recruitment periods, study designs (hospital- or population-based study), and participating rates for each study. There were 14,852 head and neck cancer cases and 22,987 controls.

Cases and controls with missing data on age, sex, or race/ethnicity, and cases with missing information on the site of origin of their cancer were excluded (332 cases and 250 controls). In total, 14,520 cases and 22,737 controls were included in the analysis. Among the cases, 3,859 were oral cancer, 4,755 were pharyngeal cancer, 1,513 were cancer of the oral cavity or pharynx not otherwise specified, 4,073 were laryngeal cancer and 320 overlapping (Table 1). Written informed consent was obtained from all study subjects and the studies were approved by relevant ethics committees at each of the institutes involved. Questionnaires were collected from all the individual studies, to assess the comparability of the collected data and of the wording of interview questions among the studies. Data from individual studies were received with personal identifiers removed. Each data item was checked for illogical or missing values and inconsistencies were resolved as necessary. Details on harmonizing questionnaire data have been published previously [2]. Briefly, the definitions for ever-smoking and drinking are different across studies. We reclassified ever tobacco smokers as those who have smoked at least 100 cigarettes or 100 cigars or 100 pipes in their lifetime. In our previous analyses, drinking ( $>3$ drinks/day) was associated with an increased HNC risk [2] among never smokers, thus we classified heavy drinker as those who have consumed alcohol three or more drinks/day.

Food questionnaires were designed by each individual study. For our analysis, we considered questionnaire wordings to group the food items (Appendix 2). In brief, four major food categories were grouped into: vegetables, fruits, animal products, and others (cereals and grains). Several food items and sub-food categories were identified within each major food categories. Two units were used in the analyses: center-specific quartiles among the controls for food groups and frequency per week (arbitrary chosen cutoffs: <once per week, 1-3 times per week, 3-7 times per week, and $\geq 7$ times per week) for single food items. A score which indicated high consumption of fruit and vegetable intake ( 0 for the lowest quartile and 3 for the highest quartile) and low red meat ( 0 for the highest quartile and 3 for lowest quartile) was created for each subject by summing up the scores in each 
food group. The association between dietary pattern scores and HNC risk was only considered for studies which contributed to all of the three food groups (fruit, vegetable, and red meat; Aviano, Italy Multicenter, Switzerland, Seattle, Tampa, Los Angeles, Puerto Rico, Latin America, Boston, US Multicenter, MSKCC, Seattle-LEO, Western Europe, and Japan).

The associations between food groups/items and HNC risk were assessed by estimating odds ratios (OR) and 95\% confidence intervals (CI) with unconditional logistic regression models for each study. Pooled ORs were estimated with a random-effects logistic regression model [38]. To adjust for the potential confounders, the models included age (5-year categories), sex, race/ethnicity (categories), center, education level (categories), packyears of cigarette smoking (continuous), duration of cigar smoking (continuous), duration of pipe smoking (continuous), intensity of alcohol drinking (continuous), and weight (kg, continuous). Information on ethnicity was not collected in the Central Europe, Saarland, and Heidelberg studies. In these studies, all subjects were classified as non-Hispanic white, since the large majority of these populations are expected to be white. Information on education was not collected in the France, Rome, and Japan studies. Weight was not available in the Seattle and Heidelberg studies. Multiple imputations with the PROC MI procedure in the SAS package was applied to impute the missing values of education, considering case-control status, age, sex, race, and study regions. For the Japan study, education was imputed by case-control status, age, and sex, according to the Asian population in the North American studies, because the socioeconomic status in Japan is expected to be similar to that in the North American countries. Stratified analyses were conducted by cancer site (oral cavity, pharynx, oropharynx, and larynx), age ( $<45$ years and $\geq 45$ years), sex, race (White, Black, Hispanic, Asian, and Brazilian), geographic region (Europe, North America, Latin America, and Asia and others), study type (hospital-based and population-based), tobacco smoking

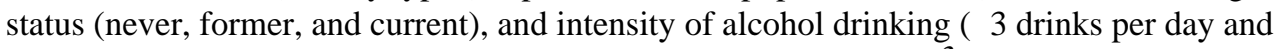
$>3$ drinks per day). Heterogeneity across stratum was assessed by $I^{2}$ statistics and Q test [39]. Subset analyses were conducted according to the completeness of dietary questionnaire (all, at least $30 \%$ completed, at least 50\% completed, and at least $80 \%$ completed) and in the studies which aimed at getting dietary habits at least one year before disease diagnosis/ interview.

Analyses were performed using SAS 9.1. Heterogeneity tests were performed by STATA SE11. All tests were two sided and statistical significance was assessed at the level of 0.05.

\section{Results}

Table 1 summarizes the characteristics of cases and controls from all studies. Overall, controls included more individuals who were women, were younger, had higher education, and had a heavier average weight than the cases.

Heterogeneity across studies was detected for almost all food groups/items. Pooled results from random-effects model were reported. Table 2 presents the OR and 95\% CI for vegetables and the $\mathrm{HNC}$ risks. Overall vegetable intake (excluding potatoes) showed an inverse association with $\mathrm{HNC}\left(4^{\text {th }}\right.$ vs. $1^{\text {st }}$ quartile: $\mathrm{OR}=0.66,95 \% \mathrm{CI}=0.49-0.90$,

$\left.\mathrm{p}_{\text {trend }}=0.01\right)$. Similar associations were observed for non-starchy vegetables, especially green vegetables and allium vegetables, but not for cruciferous vegetables. Consumption of green salad, lettuce, and fresh tomatoes more than 7 times per week were associated with lower HNC risks compared to consumption less than once per week. Potato intake was associated with an increased risk of $\mathrm{HNC}(\mathrm{OR}=1.24,95 \% \mathrm{CI}=1.05-1.46)$, especially for fried potatoes $(\mathrm{OR}=2.97,95 \% \mathrm{CI}=1.40-6.32)$. 
Lower head and neck cancer risks were also observed for higher fruit intake (Table 3). Individuals who had the highest overall fruit intake had lower HNC risk $\left(4^{\text {th }}\right.$ vs. $1^{\text {st }}$ quartile $\mathrm{OR}=0.52,95 \% \mathrm{CI}=0.43-0.62, \mathrm{p}_{\text {trend }}<0.01$ ), especially with the highest intake of citrus fruits and apples and pears. On the other hand, higher intake of several meat products showed an increased risk for HNC (Table 4), notably for red meat (beef + pork: OR $=1.40,95 \%$ $\left.\mathrm{CI}=1.13-1.74, \mathrm{p}_{\text {trend }}=0.13\right)$ and processed meats $(\mathrm{OR}=1.37,95 \% \mathrm{CI}=1.14-1.65$, $\mathrm{p}_{\text {trend }}<0.01$ ), while white meat (poultry + fish) seemed to be inversely associated (OR=0.68, $\left.95 \% \mathrm{CI}=0.55-0.84, \mathrm{p}_{\text {trend }}<0.01\right)$. Higher egg consumption was also associated with higher $\mathrm{HNC}$ risk $(\mathrm{OR}=1.44,95 \% \mathrm{CI}=1.12-1.86)$. No associations between cereals and grains and HNC risk were observed in these analyses (Table 5). Appendix 3 and Appendix Figure 1-6 show the results from the stratified analyses for the major findings. Ethnicity and study region seemed to be the major source of heterogeneity $\left(I^{2}=73 \%\right.$ for race and $83 \%$ for region for the association between red meat intake and HNC risk, and 59\% for race, and 53\% for region for the association with vegetable intake). A higher dietary pattern score, which indicated higher consumption of fruit and vegetable and lower consumption of red meat, was associated with lower HNC risk (Table 6, OR for each score increment $=0.90,95 \%$ $\left.\mathrm{CI}=0.84-0.97, \mathrm{p}_{\text {trend }}=0.01\right)$.

Table 7 presents the association between major food groups and $\mathrm{HNC}$ risks among subjects who were never smokers and light drinkers. Fruit intake was inversely associated with HNC risk $\left(4^{\text {th }}\right.$ vs. $1^{\text {st }}$ quartile: $\left.\mathrm{OR}=0.66,95 \% \mathrm{CI}=0.48-0.92, \mathrm{p}_{\text {trend }}=0.27\right)$, red meat intake was positively associated with $\mathrm{HNC}$ risk $\left(\mathrm{OR}=1.55,95 \% \mathrm{CI}=1.15-2.10, \mathrm{p}_{\text {trend }}=0.19\right)$, and a high score was associated with lower $\mathrm{HNC}$ risk (7-9 vs. $0-2$, $\mathrm{OR}=0.48,95 \% \mathrm{CI}=0.32-0.74$, $\left.\mathrm{p}_{\text {trend }}=0.04\right)$.

\section{Discussion}

Results from our data support the conclusions from earlier studies that a higher frequency of fruit and vegetable intake were inversely associated with HNC risk [9-15,19,22,24,26$28,30,40-47]$ and red meat and processed meat were positively associated with increased risks of HNC $[9,15,16,20-22,28,31,40]$. The associations were consistent among subjects who were never smokers and light drinkers. A dietary pattern high in fruit and vegetable and low in red meat intake was associated with decreased HNC risk. Ethnicity and study region could be the major sources of heterogeneity.

The associations between vegetable and HNC were observed mostly in smokers or heavy drinkers but not in never-smokers and light drinkers; this could be explained by residual confounding from smoking or drinking because smokers tend to consume more energy from alcohol and less energy from vegetables [48] and the measurement error might be correlated between diet and smoking behavior. In the present study, we adjusted for packyears of cigarette smoking as well as for duration of cigar and pipe use and drinking intensity for alcohol consumption, thus the residual confounding effect should have been minimized, although it might not be completely eliminated. Removing smoking and drinking variables from the regression model, the OR was 0.56 (95\% CI=0.41-0.76) comparing the $4^{\text {th }}$ to the $1^{\text {st }}$ quartile; the ORs were $0.64(95 \% \mathrm{CI}=0.47-0.88)$ if adjusted for smoking variables and 0.59 (95\% CI=0.44-0.79) if adjusted for drinking variable. All of these estimates were stronger than the full model estimate, $\mathrm{OR}=0.66,95 \% \mathrm{CI}=0.49-0.90$ (Table 2). Reductions of the HNC risk in never smokers and light drinkers were observed with non-starchy vegetables and carrots (data not shown). An explanation for the limited association in never smokers could be that nutrients in vegetables, such as vitamin $\mathrm{C}$, vitamin $\mathrm{E}$, folate, fibre, and flavonoids, could modulate the carcinogenic effects of smoking by reducing the smokeinduced oxidative damage or inflammatory responses [49-52], thus the effects can only be observed in smokers. An alternative explanation is that the etiology of HNC in never 
smokers might be different from that in smokers [53-55], such as HPV, an established risk factor for oropharyngeal cancers [56]. A study has reported that HPV infection may modify the association between fruit intake and HNC risk [57].

We observed heterogeneity in the Asian $\left(I^{2}=58.8 \%, \mathrm{p}=0.033\right.$; Appendix figure 1$)$. The $\mathrm{p}$ for heterogeneity was 0.74 if removing the Asians from the meta-analysis. Nevertheless, higher vegetable intake was associated with lower HNC risk in the Asian population.

Fruit intake was inversely associated with HNC in the current analyses, as previously reported $[9,10,12,15,19,22,24,26-28,30,40-47,58]$, especially for citrus fruits, and apples and pears. Smoking status did not seem to influence the associations between fruit and HNC risk in the current analyses, as reported by other studies [10,27,28,30,41,42,58]. The inverse associations from fruit intake were consistent across subsites of HNC, strata of age and sex, and study type, i.e. population controls and hospital controls (Appendix Figure 2).

In terms of other food groups, we observed increased risks for a high frequency of red meat consumption (including beef and pork) and processed meat. Red meat and processed meat are convincing causes of colorectal cancer and suggestive causes of esophageal and lung cancers $[17,21,59,60]$. The mechanisms behind red meat and processed meat and cancer risks include iron over-storage or the oxidative stress resulting from free radicals [17] and the carcinogens generated or added during meat preparation [61] or preservation [17]. This increased risk was observed not only by comparing the relative high to the relative low consumption but also by comparing individuals who ate beef or pork greater than seven times per week to those who ate less than once per week.

On the other hand, we observed an inverse association between red meat and HNC risk from studies in Asia. This could be because that the Japanese population (the only study contributed to this sub-analyses) generally consumes less red meat [62] and more vegetables $[17,63]$ than populations from the North America or Western Europe.

In contrast, we observed an inverse association between white meat (a combination of poultry, fish, and shellfish) and HNC. The epidemiological evidence for the association between white meat and $\mathrm{HNC}$ has been inconsistent. A prospective investigation in the US (the NIH-AARP cohort, [64]) found an inverse association between poultry and fish intake and digestive and respiratory cancers, including a strong inverse association between poultry intake and laryngeal cancer among women. The authors attributed the inverse association to the red meat substitution effects. Relative to red meat, poultry and fish are lower in saturated fat and heme iron and may result in less exposure to free radicals or carcinogens generated during the processing of red meat or processed meat [64]. Alternatively, poultry is high in zinc, which might protect against oxygen radicals and lipid peroxidation that can promote carcinogenesis [65]. Fish contains omega-3 fatty acids, which is associated with better immune function [66]. However, poultry and fish intake could be an indicator of general nutritional status. Nevertheless, the heterogeneity was not evident in any subgroups (Appendix Figure 4) and a decreasing trend (though not statistical significant) was observed among never smoker and light drinkers (Table 7). Mutual adjustment for red and white meat did not change the associations between HNC and white and red meat substantially.

We also observed an increased risk for consuming more than three eggs per week compare to less than one egg per week. The association has been observed previously, but results have been inconsistent $[15,16,25,27-29,31,40,44-47,67-69]$. We performed principal component analysis on food items for each study in our consortium. Egg consumption showed an association with meat intake in most of the studies: Milan, Aviano, Italy Multicenter, Switzerland, Central Europe, Seattle, North Carolina, Tampa, Los Angeles, Latin America, Boston, US Multicenter, MSKCC, Seattle-LEO, and Japan. On the other 
hand, there were associations between egg intake and fruit and vegetable intakes for other studies: France, Puerto Rico, IARC Multicenter, and Saarland. Egg consumption might be a marker of special diet requirements. However, stratification by fruit, vegetable, red meat, or processed meat intake did not alter the observed positive associations.

Because high intake of some dietary items might be correlated with lower intake of other items, we addressed this pattern with a score, which reflects high intake of fruit and vegetable and low intake of red meat. We observed that a higher score was associated with a reduced HNC risk. The association was consistent across subsites of HNC, sex, race, region, type of controls, dietary information at least one year before diagnosis or interview, and completeness of FFQ (Appendix Figure 6) and was retained in the never smoker and light drinker population (Table 7). This observation further strengthens the fact that healthier dietary habit, i.e. high fruit and vegetable and low red meat intake, plays a role in HNC.

Although our study included a large numbers of subjects from studies from different geographic areas with different dietary patterns, these properties may be also a limitation of the study. Though we assessed that heterogeneity may have partly been due to study design or characteristics of the study populations, there were other potential source of heterogeneity that we were not able to control. First, questionnaires were not standardized but each study had its own questionnaire aiming at their specific population and testing for different hypotheses. To overcome this limitation, we have tried to group the detailed food items into broad food groups and analyzed the food groups and food items in both relative (quartiles) and absolute frequencies (times/week), using a random-effect model. Second, the quantity of food consumed was not available for most of the studies. All of the above may contribute to the observed heterogeneity across studies. Other limitations include: total energy intake, an important confounder for dietary intake analysis, was not available for all studies. We adjusted for weight to address this limitation because weight would reflect the energy intake in middle-aged adults [70]. A subset analysis restricted to studies that provided total energy intake showed that the point estimates did not substantially change after adjustment for total energy intake or weight. Multiple comparisons were made; some of the observed association might be due to chance. Although there were some limitations from difficulties in standardizing questionnaires, our study provided unique opportunities to explore differences in subgroups and potential sources of heterogeneity. Unlike meta-analysis, we had individual level data in our database. All data were evaluated and standardized across all studies [2], thus we were able to adjust the potential confounders consistently.

Generally speaking, previous case-control studies on diet and HNC risks reported stronger associations than did cohort studies [10,12, 22]. While recall bias could result in relatively strong associations in case-control studies, behavior change after recruitment in cohort studies could also dilute the associations. In addition, the inclusion criteria for the control group might alter the true distribution of exposures in the base population (selection bias). Hospital-based studies excluding controls with diseases that share risk factors with HNC might increase the selection probability of unexposed controls, if the exposure is associated with the risk factors, and bias the estimates away from null. Nevertheless, no heterogeneity was observed between population- and hospital-based studies, and case-control studies and cohort studies yield similar messages on diet and HNC risks, i.e. lower HNC risks with higher fruit and vegetable consumption and lower meat consumption, especially red meat. Our study further provides evidence of these associations among never smokers and light drinkers.

\section{Supplementary Material}

Refer to Web version on PubMed Central for supplementary material. 


\section{Acknowledgments}

Shu-Chun Chuang worked on this study during the tenure of a Special Training Award from the International Agency for Research on Cancer.

\section{Funding}

This INHANCE Consortium was supported by a grant from the US National Institutes of Health (NIH), National Cancer Institute (NCI) (R03CA113157) and National Institute for Dental and Craniofacial Research (NIDCR; R03DE016611). The individual studies were funded by the following grants: Milan study: Italian Association for Research on Cancer (AIRC). Aviano: Italian Association for Research on Cancer (AIRC), Italian League against Cancer and Italian Ministry of Research. France study: Swiss League against Cancer (KFS1069-09-2000), Fribourg League against Cancer (FOR381.88), Swiss Cancer Research (AKT 617) and Gustave-Roussy Institute (88D28). Italy Multicenter study: Italian Association for Research on Cancer (AIRC), Italian League against Cancer and Italian Ministry of Research. Swiss study: Swiss League against Cancer and the Swiss Research against Cancer/ Oncosuisse (KFS-700, OCS-1633). Central Europe study: World Cancer Research Fund and the European Commission's INCO-COPERNICUS Program (Contract No. IC15-CT98-0332). Seattle study: National Institutes of Health (NIH) US (R01CA048996, R01DE012609). North Carolina study: National Institutes of Health (NIH) US (R01CA61188), and in part by a grant from the National Institute of Environmental Health Sciences (P30ES010126). Tampa study: National Institutes of Health (NIH) US (P01CA068384, K07CA104231, R01DE13158). Los Angeles study: National Institute of Health (NIH) US (P50CA90388, R01DA11386, R03CA77954, T32CA09142, U01CA96134, R21ES011667) and the Alper Research Program for Environmental Genomics of the UCLA Jonsson Comprehensive Cancer Center. Puerto Rico study: jointly funded by National Institutes of Health (NCI) US and NIDCR intramural programs. Latin America study: Fondo para la Investigacion Cientifica y Tecnologica (FONCYT) Argentina, IMIM (Barcelona), Fundac, a o de Amparo a` Pesquisa no. Estado de Sa ̃ Paulo (FAPESP) (No 01/01768-2), and European Commission (IC18-CT97-0222). IARC Multicenter study: Fondo de Investigaciones Sanitarias (FIS) of the Spanish Government (FIS 97/0024, FIS 97/0662, BAE 01/5013), International Union Against Cancer (UICC), and Yamagiwa-Yoshida Memorial International Cancer Study Grant. Boston study: National Institutes of Health (NIH) US (R01CA078609, R01CA100679). Rome study: AIRC (Italian Agency for Research on Cancer). US Multicenter study: The Intramural Program of the National Cancer Institute, National Institutes of Health, USA. MSKCC study: NIH (R01CA51845). Seattle-LEO study: NIH(R01CA30022). Western Europe Study: European Commission's $5^{\text {th }}$ Framework Program (Contract No. QLK1-2001-00182), Italian Association for Cancer Research, Compagnia di San Paolo/ FIRMS, Region Piemonte, and Padova University (Contract No. CPDA057222). Saarland study: Ministry of Science, Research and Arts Baden-Württemberg. Heidelberg study: Grant No. 01GB9702/3 from the German Ministry of Education and Research. Japan study: Scientific Research grant from the Ministry of Education, Science, Sports, Culture and Technology of Japan (17015052) and grant for the Third-Term Comprehensive 10-Year Strategy for Cancer Control from the Ministry of Health, Labor and Welfare of Japan (H20-002)

\section{Reference List}

1. Ferlay, J.; Shin, HR.; Bray, F.; Forman, D.; Mathers, C.; Parkin, DM. GLOBOCAN 2008, Cancer Incidence and Mortality Worldwide: IARC CancerBase No. 10. Lyon, France: International Agency for Research on Cancer; 2010. http://globocan.iarc.fr

2. Hashibe M, Brennan P, Benhamou S, et al. Alcohol drinking in never users of tobacco, cigarette smoking in never drinkers, and the risk of head and neck cancer: pooled analysis in the International Head and Neck Cancer Epidemiology Consortium. J Natl Cancer Inst. 2007; 99(10):777-789. [PubMed: 17505073]

3. Hashibe M, Brennan P, Chuang SC, et al. Interaction between tobacco and alcohol use and the risk of head and neck cancer: pooled analysis in the International Head and Neck Cancer Epidemiology Consortium. Cancer Epidemiol Biomarkers Prev. 2009; 18(2):541-550. [PubMed: 19190158]

4. Secretan B, Straif K, Baan R, et al. A review of human carcinogens--Part E: tobacco, areca nut, alcohol, coal smoke, and salted fish. Lancet Oncol. 2009; 10(11):1033-1034. [PubMed: 19891056]

5. Lee YC, Boffetta P, Sturgis EM, et al. Involuntary smoking and head and neck cancer risk: pooled analysis in the International Head and Neck Cancer Epidemiology Consortium. Cancer Epidemiol Biomarkers Prev. 2008; 17(8):1974-1981. [PubMed: 18708387]

6. IARC Working Group. Human Papillomaviruses. 2007:1-689.

7. Gaudet MM, Olshan AF, Chuang SC, et al. Body mass index and risk of head and neck cancer in a pooled analysis of case-control studies in the International Head and Neck Cancer Epidemiology (INHANCE) Consortium. Int J Epidemiol. 2010; 39(4):1091-1102. [PubMed: 20123951] 
8. Negri E, Boffetta P, Berthiller J, et al. Family history of cancer: pooled analysis in the International Head and Neck Cancer Epidemiology Consortium. Int J Cancer. 2009; 124(2):394-401. [PubMed: 18814262]

9. Lagiou P, Talamini R, Samoli E, et al. Diet and upper-aerodigestive tract cancer in Europe: the ARCAGE study. Int J Cancer. 2009; 124(11):2671-2676. [PubMed: 19230023]

10. Freedman ND, Park Y, Subar AF, et al. Fruit and vegetable intake and head and neck cancer risk in a large United States prospective cohort study. Int J Cancer. 2008; 122(10):2330-2336. [PubMed: 18092323]

11. Sapkota A, Hsu CC, Zaridze D, et al. Dietary risk factors for squamous cell carcinoma of the upper aerodigestive tract in central and eastern Europe. Cancer Causes Control. 2008; 19(10):11611170. [PubMed: 18512121]

12. Boeing H, Dietrich T, Hoffmann K, et al. Intake of fruits and vegetables and risk of cancer of the upper aero-digestive tract: the prospective EPIC-study. Cancer Causes Control. 2006; 17(7):957969. [PubMed: 16841263]

13. Edefonti V, Bravi F, La Vecchia C, et al. Nutrient-based dietary patterns and the risk of oral and pharyngeal cancer. Oral Oncol. 2010; 46(5):343-348. [PubMed: 20226721]

14. Edefonti V, Bravi F, Garavello W, et al. Nutrient-based dietary patterns and laryngeal cancer: evidence from an exploratory factor analysis. Cancer Epidemiol Biomarkers Prev. 2010; 19(1):1827. [PubMed: 20056619]

15. Bosetti C, La Vecchia C, Talamini R, et al. Food groups and laryngeal cancer risk: a case-control study from Italy and Switzerland. Int J Cancer. 2002; 100(3):355-360. [PubMed: 12115553]

16. Franceschi S, Favero A, Conti E, et al. Food groups, oils and butter, and cancer of the oral cavity and pharynx. Br J Cancer. 1999; 80(3-4):614-620. [PubMed: 10408875]

17. World Cancer Research Fund/American Institute for Cancer Research. Food, Nutrition, Physical Activity, and the Prevention of Cancer: a Global Perspective. Washington, DC: AICR; 2007.

18. Lam TK, Cross AJ, Consonni D, et al. Intakes of red meat, processed meat, and meat mutagens increase lung cancer risk. Cancer Res. 2009; 69(3):932-939. [PubMed: 19141639]

19. La Vecchia C, Chatenoud L, Franceschi S, Soler M, Parazzini F, Negri E. Vegetables and fruit and human cancer: update of an Italian study. Int J Cancer. 1999; 82(1):151-152. [PubMed: 10360835]

20. Aune D, De SE, Ronco A, et al. Meat consumption and cancer risk: a case-control study in Uruguay. Asian Pac J Cancer Prev. 2009; 10(3):429-436. [PubMed: 19640186]

21. Tavani A, La Vecchia C, Gallus S, et al. Red meat intake and cancer risk: a study in Italy. Int J Cancer. 2000; 86(3):425-428. [PubMed: 10760833]

22. Lucenteforte E, Garavello W, Bosetti C, La Vecchia C. Dietary factors and oral and pharyngeal cancer risk. Oral Oncol. 2009; 45(6):461-467. [PubMed: 18990606]

23. Peters ES, Luckett BG, Applebaum KM, Marsit CJ, McClean MD, Kelsey KT. Dairy products, leanness, and head and neck squamous cell carcinoma. Head Neck. 2008; 30(9):1193-1205. [PubMed: 18642285]

24. Kreimer AR, Randi G, Herrero R, Castellsague X, La VC, Franceschi S. Diet and body mass, and oral and oropharyngeal squamous cell carcinomas: analysis from the IARC multinational casecontrol study. Int J Cancer. 2006; 118(9):2293-2297. [PubMed: 16331628]

25. Franceschi S, Bidoli E, Baron AE, et al. Nutrition and cancer of the oral cavity and pharynx in north-east Italy. Int J Cancer. 1991; 47(1):20-25. [PubMed: 1985874]

26. Zheng W, Blot WJ, Shu XO, et al. Risk factors for oral and pharyngeal cancer in Shanghai, with emphasis on diet. Cancer Epidemiol Biomarkers Prev. 1992; 1(6):441-448. [PubMed: 1302555]

27. Sanchez MJ, Martinez C, Nieto A, et al. Oral and oropharyngeal cancer in Spain: influence of dietary patterns. Eur J Cancer Prev. 2003; 12(1):49-56. [PubMed: 12548110]

28. Rajkumar T, Sridhar H, Balaram P, et al. Oral cancer in Southern India: the influence of body size, diet, infections and sexual practices. Eur J Cancer Prev. 2003; 12(2):135-143. [PubMed: 12671537]

29. Lissowska J, Pilarska A, Pilarski P, et al. Smoking, alcohol, diet, dentition and sexual practices in the epidemiology of oral cancer in Poland. Eur J Cancer Prev. 2003; 12(1):25-33. [PubMed: 12548107] 
30. Tavani A, Gallus S, La VC, et al. Diet and risk of oral and pharyngeal cancer. An Italian casecontrol study. Eur J Cancer Prev. 2001; 10(2):191-195. [PubMed: 11330465]

31. Garrote LF, Herrero R, Reyes RM, et al. Risk factors for cancer of the oral cavity and oro-pharynx in Cuba. Br J Cancer. 2001; 85(1):46-54. [PubMed: 11437401]

32. Blot WJ, McLaughlin JK, Winn DM, et al. Smoking and drinking in relation to oral and pharyngeal cancer. Cancer Res. 1988; 48(11):3282-3287. [PubMed: 3365707]

33. Park JY, Schantz SP, Lazarus P. Epoxide hydrolase genotype and orolaryngeal cancer risk: interaction with GSTM1 genotype. Oral Oncol. 2003; 39(5):483-490. [PubMed: 12747973]

34. Anantharaman D, Chaubal PM, Kannan S, Bhisey RA, Mahimkar MB. Susceptibility to oral cancer by genetic polymorphisms at CYP1A1, GSTM1 and GSTT1 loci among Indians: tobacco exposure as a risk modulator. Carcinogenesis. 2007; 28(7):1455-1462. [PubMed: 17307803]

35. Haug U, Hillebrand T, Bendzko P, et al. Mutant-enriched PCR and allele-specific hybridization reaction to detect K-ras mutations in stool DNA: high prevalence in a large sample of older adults. Clin Chem. 2007; 53(4):787-790. [PubMed: 17317884]

36. Ramroth H, Dietz A, Becher H. Interaction effects and population-attributable risks for smoking and alcohol on laryngeal cancer and its subsites. A case-control study from Germany. Methods Inf Med. 2004; 43(5):499-504. [PubMed: 15702209]

37. Suzuki T, Matsuo K, Hasegawa Y, et al. One-carbon metabolism-related gene polymorphisms and risk of head and neck squamous cell carcinoma: case-control study. Cancer Sci. 2007; 98(9):14391446. [PubMed: 17596206]

38. DerSimonian R, Laird N. Meta-analysis in clinical trials. Control Clin Trials. 1986; 7(3):177-188. [PubMed: 3802833]

39. Higgins JP, Thompson SG, Deeks JJ, Altman DG. Measuring inconsistency in meta-analyses. BMJ. 2003; 327(7414):557-560. [PubMed: 12958120]

40. Levi F, Pasche C, La VC, Lucchini F, Franceschi S, Monnier P. Food groups and risk of oral and pharyngeal cancer. Int J Cancer. 1998; 77(5):705-709. [PubMed: 9688303]

41. La Vecchia C, Negri E, D'Avanzo B, Franceschi S, Decarli A, Boyle P. Dietary indicators of laryngeal cancer risk. Cancer Res. 1990; 50(15):4497-4500. [PubMed: 2369728]

42. La Vecchia C, Negri E, D'Avanzo B, Boyle P, Franceschi S. Dietary indicators of oral and pharyngeal cancer. Int J Epidemiol. 1991; 20(1):39-44. [PubMed: 2066242]

43. Kjaerheim K, Gaard M, Andersen A. The role of alcohol, tobacco, and dietary factors in upper aerogastric tract cancers: a prospective study of 10,900 Norwegian men. Cancer Causes Control. 1998; 9(1):99-108. [PubMed: 9486469]

44. Takezaki T, Hirose K, Inoue M, et al. Tobacco, alcohol and dietary factors associated with the risk of oral cancer among Japanese. Jpn J Cancer Res. 1996; 87(6):555-562. [PubMed: 8766517]

45. De Stefani E, eo-Pellegrini H, Mendilaharsu M, Ronco A. Diet and risk of cancer of the upper aerodigestive tract--I. Foods. Oral Oncol. 1999; 35(1):17-21. [PubMed: 10211305]

46. De Stefani E, Boffetta P, Ronco AL, et al. Dietary patterns and risk of cancer of the oral cavity and pharynx in Uruguay. Nutr Cancer. 2005; 51(2):132-139. [PubMed: 15860434]

47. Kapil U, Singh P, Bahadur S, Dwivedi SN, Singh R, Shukla N. Assessment of risk factors in laryngeal cancer in India: a case-control study. Asian Pac J Cancer Prev. 2005; 6(2):202-207. [PubMed: 16101334]

48. Dyer AR, Elliott P, Stamler J, Chan Q, Ueshima H, Zhou BF. Dietary intake in male and female smokers, ex-smokers, and never smokers: the INTERMAP study. J Hum Hypertens. 2003; 17(9): 641-654. [PubMed: 13679954]

49. Panda K, Chattopadhyay R, Chattopadhyay DJ, Chatterjee IB. Vitamin C prevents cigarette smoke-induced oxidative damage in vivo. Free Radic Biol Med. 2000; 29(2):115-124. [PubMed: 10980400]

50. Northrop-Clewes CA, Thurnham DI. Monitoring micronutrients in cigarette smokers. Clin Chim Acta. 2007; 377(1-2):14-38. [PubMed: 17045981]

51. Garavello W, Rossi M, McLaughlin JK, et al. Flavonoids and laryngeal cancer risk in Italy. Ann Oncol. 2007; 18(6):1104-1109. [PubMed: 17372161] 
52. Fioretti F, Bosetti C, Tavani A, Franceschi S, La Vecchia C. Risk factors for oral and pharyngeal cancer in never smokers. Oral Oncol. 1999; 35(4):375-378. [PubMed: 10645401]

53. Dahlstrom KR, Little JA, Zafereo ME, Lung M, Wei Q, Sturgis EM. Squamous cell carcinoma of the head and neck in never smoker-never drinkers: a descriptive epidemiologic study. Head Neck. 2008; 30(1):75-84. [PubMed: 17694557]

54. Farshadpour F, Hordijk GJ, Koole R, Slootweg PJ. Non-smoking and non-drinking patients with head and neck squamous cell carcinoma: a distinct population. Oral Dis. 2007; 13(2):239-243. [PubMed: 17305629]

55. Lajer CB, von BC. The role of human papillomavirus in head and neck cancer. APMIS. 2010; 118(6-7):510-519. [PubMed: 20553531]

56. Bouvard V, Baan R, Straif K, et al. A review of human carcinogens--Part B: biological agents. Lancet Oncol. 2009; 10(4):321-322. [PubMed: 19350698]

57. Meyer MS, Applebaum KM, Furniss CS, et al. Human papillomavirus-16 modifies the association between fruit consumption and head and neck squamous cell carcinoma. Cancer Epidemiol Biomarkers Prev. 2008; 17(12):3419-3426. [PubMed: 19064557]

58. Foschi R, Pelucchi C, Dal Maso L, et al. Citrus fruit and cancer risk in a network of case-control studies. Cancer Causes Control. 2010; 21(2):237-242. [PubMed: 19856118]

59. La Vecchia C, Tavani A, Franceschi S, Levi F, Corrao G, Negri E. Epidemiology and prevention of oral cancer. Oral Oncol. 1997; 33(5):302-312. [PubMed: 9415327]

60. Levi F, Pasche C, Lucchini F, Bosetti C, La Vecchia C. Processed meat and the risk of selected digestive tract and laryngeal neoplasms in Switzerland. Ann Oncol. 2004; 15(2):346-349. [PubMed: 14760132]

61. Zheng W, Lee SA. Well-done meat intake, heterocyclic amine exposure, and cancer risk. Nutr Cancer. 2009; 61(4):437-446. [PubMed: 19838915]

62. Tzoulaki I, Brown IJ, Chan Q, et al. Relation of iron and red meat intake to blood pressure: cross sectional epidemiological study. BMJ. 2008; 337:a258. [PubMed: 18632704]

63. Zhou BF, Stamler J, Dennis B, et al. Nutrient intakes of middle-aged men and women in China, Japan, United Kingdom, and United States in the late 1990s: the INTERMAP study. J Hum Hypertens. 2003; 17(9):623-630. [PubMed: 13679952]

64. Daniel CR, Cross AJ, Graubard BI, Hollenbeck A, Park Y, Sinha R. Prospective investigation of poultry and fish intake in relation to cancer risk. Cancer Prev Res (Phila). 2011

65. Rogers MA, Thomas DB, Davis S, Vaughan TL, Nevissi AE. A case-control study of element levels and cancer of the upper aerodigestive tract. Cancer Epidemiol Biomarkers Prev. 1993; 2(4): 305-312. [PubMed: 8348053]

66. MacLean CH, Newberry SJ, Mojica WA, et al. Effects of omega-3 fatty acids on cancer risk: a systematic review. JAMA. 2006; 295(4):403-415. [PubMed: 16434631]

67. Nair U, Bartsch H. Metabolic polymorphisms as susceptibility markers for lung and oral cavity cancer. IARC Sci Publ. 2001; 154:271-290. [PubMed: 11220667]

68. Aune D, De SE, Ronco AL, et al. Egg consumption and the risk of cancer: a multisite case-control study in Uruguay. Asian Pac J Cancer Prev. 2009; 10(5):869-876. [PubMed: 20104980]

69. Bosetti C, Talamini R, Levi F, et al. Fried foods: a risk factor for laryngeal cancer? Br J Cancer. 2002; 87(11):1230-1233. [PubMed: 12439711]

70. Willett WC, Howe GR, Kushi LH. Adjustment for total energy intake in epidemiologic studies. Am J Clin Nutr. 1997; 65(4 Suppl):1220S-1228S. [PubMed: 9094926] 


\section{Table 1}

Characteristics of the study population

\begin{tabular}{|c|c|c|c|c|}
\hline & \multicolumn{2}{|c|}{ Cases } & \multicolumn{2}{|c|}{ Controls } \\
\hline & $\mathbf{N}$ & $\%$ & $\mathbf{N}$ & $\%$ \\
\hline Total & 14520 & & 22737 & \\
\hline \multicolumn{5}{|l|}{ Age } \\
\hline$<40$ & 527 & 3.6 & 1361 & 6.0 \\
\hline $40-45$ & 726 & 5.0 & 1380 & 6.1 \\
\hline $45-50$ & 1420 & 9.8 & 2188 & 9.6 \\
\hline $50-55$ & 2140 & 14.7 & 3347 & 4.7 \\
\hline $55-60$ & 2680 & 18.5 & 3869 & 17.0 \\
\hline $60-65$ & 2560 & 17.6 & 3728 & 16.4 \\
\hline $65-70$ & 2138 & 14.7 & 3195 & 14.1 \\
\hline $70-75$ & 1516 & 10.4 & 2409 & 10.6 \\
\hline$>=75$ & 813 & 5.6 & 1260 & 5.5 \\
\hline \multicolumn{5}{|l|}{ Sex } \\
\hline Men & 11443 & 78.8 & 16457 & 72.4 \\
\hline Women & 3077 & 21.2 & 6280 & 27.6 \\
\hline \multicolumn{5}{|l|}{ Race } \\
\hline White & 10341 & 71.2 & 16069 & 70.7 \\
\hline Black & 543 & 3.7 & 653 & 2.9 \\
\hline Hispanic & 155 & 1.1 & 361 & 1.6 \\
\hline Asia & 1146 & 7.9 & 3764 & 16.6 \\
\hline Other & 144 & 1.0 & 184 & 0.8 \\
\hline Brazilian & 2191 & 15.1 & 1706 & 7.5 \\
\hline \multicolumn{5}{|l|}{ Education } \\
\hline None & 497 & 3.4 & 344 & 1.5 \\
\hline Junior High School & 5440 & 37.5 & 7307 & 32.1 \\
\hline Some High School & 2538 & 17.5 & 3054 & 13.4 \\
\hline High School & 1366 & 9.4 & 1865 & 8.2 \\
\hline Some College & 2009 & 13.8 & 3598 & 15.8 \\
\hline Some Graduate & 1027 & 7.1 & 2558 & 11.3 \\
\hline Missing & 1643 & 11.3 & 4011 & 17.6 \\
\hline \multicolumn{5}{|l|}{ Subtype } \\
\hline Oral cavity & 3859 & 26.6 & & \\
\hline Pharynx & 4755 & 32.7 & & \\
\hline Oral/pharynx NOS & 1513 & 10.4 & & \\
\hline Larynx & 4073 & 28.1 & & \\
\hline Head and neck NOS & 320 & 2.2 & & \\
\hline
\end{tabular}

Cancer Causes Control. Author manuscript; available in PMC 2013 May 15. 


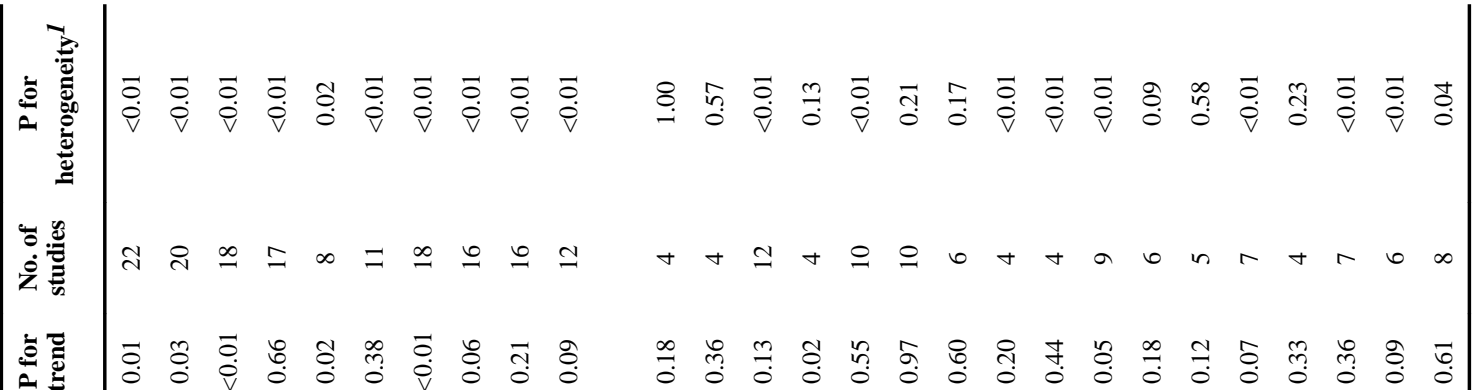

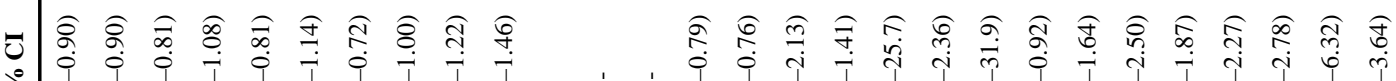

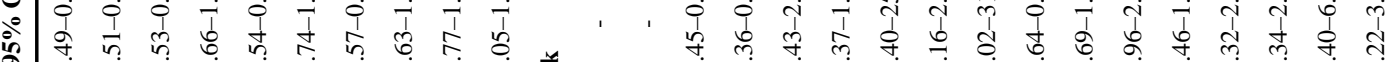
ॠ 馬

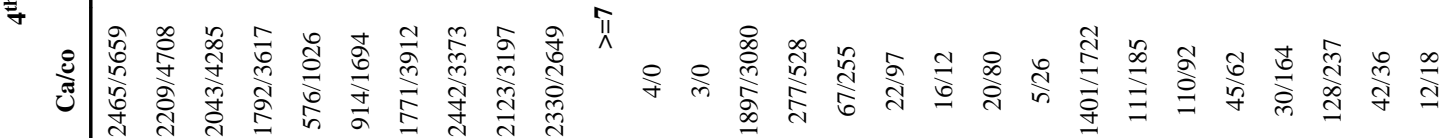

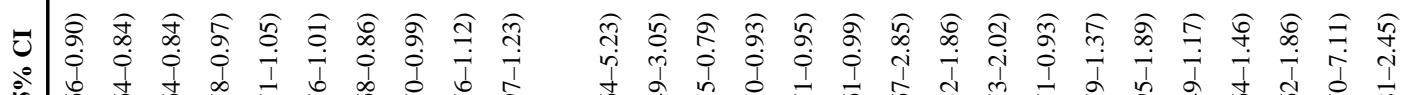

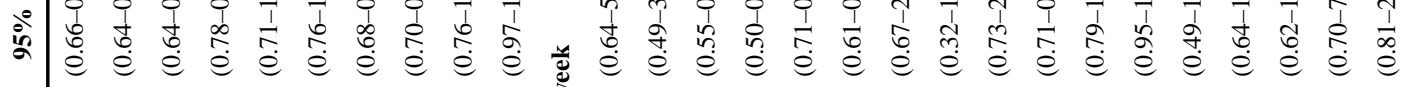

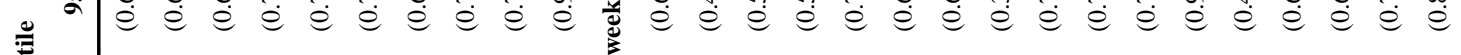
吾 吾

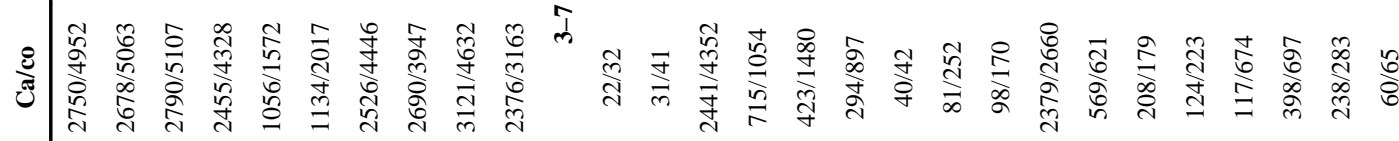

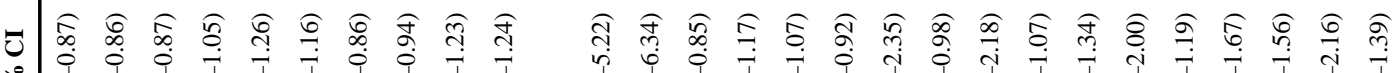

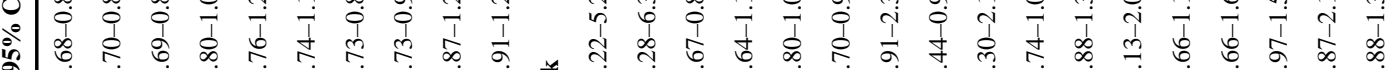
๘ 恶 券衤 त्ञ

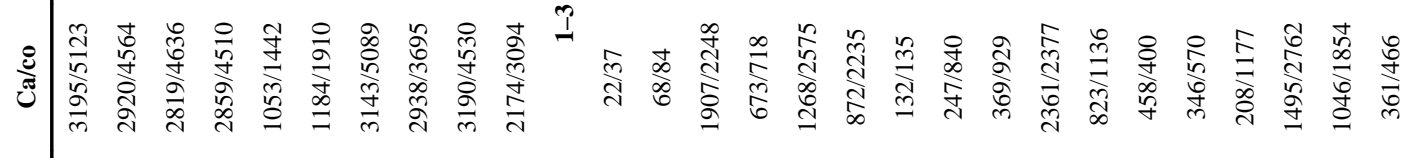

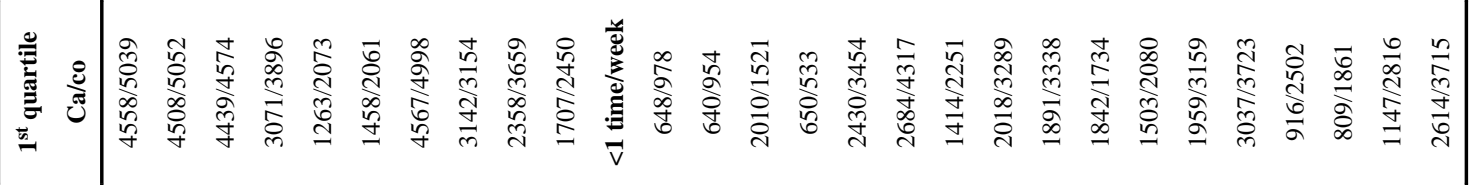
๙ั ్ㅡ 告

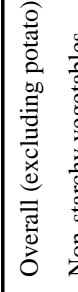

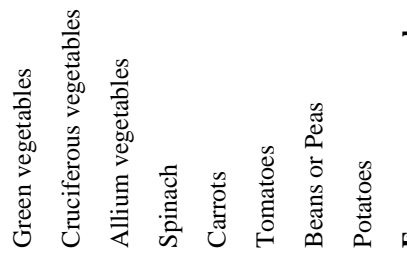

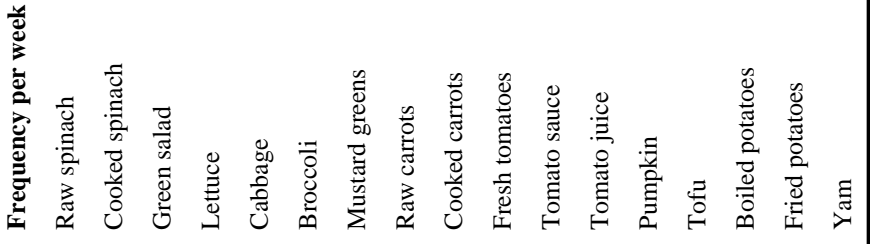




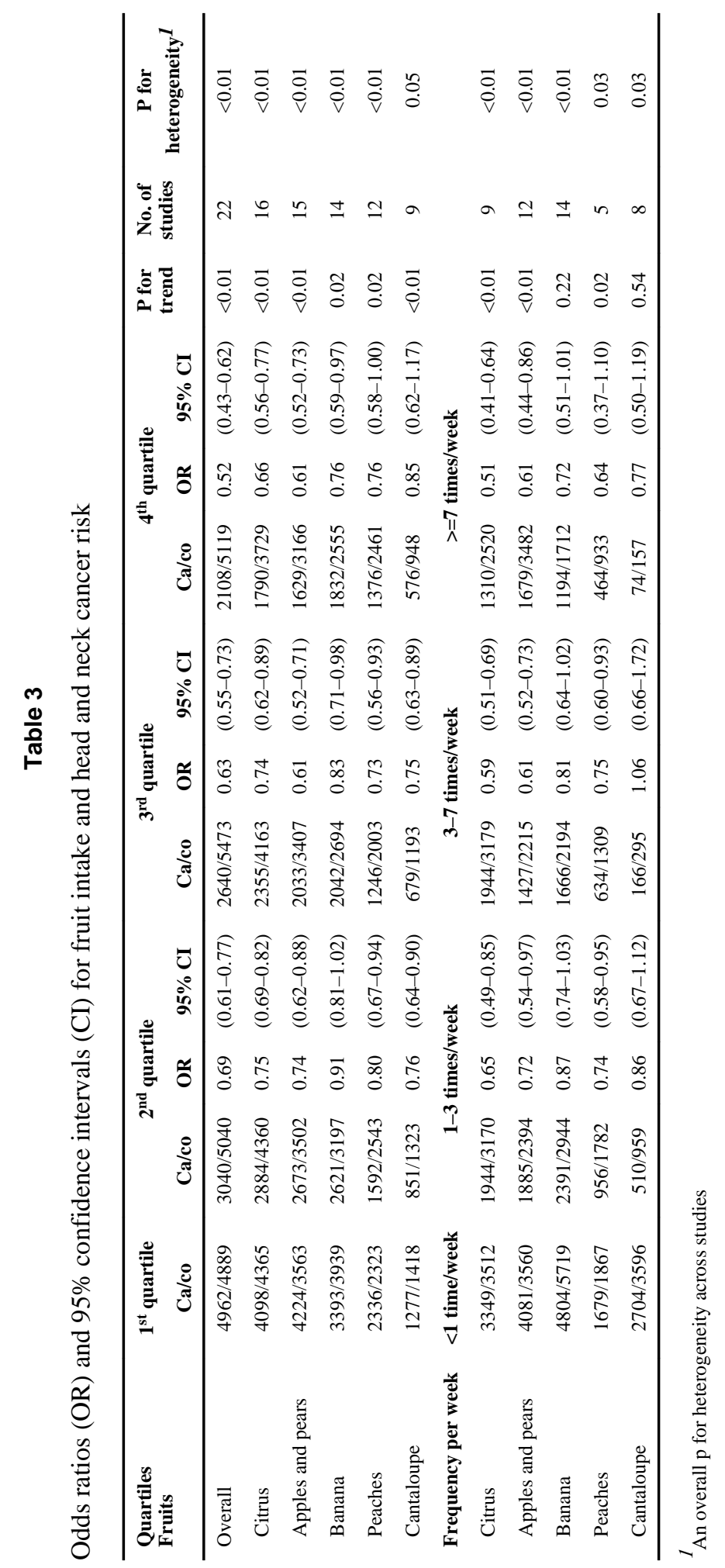

Cancer Causes Control. Author manuscript; available in PMC 2013 May 15. 


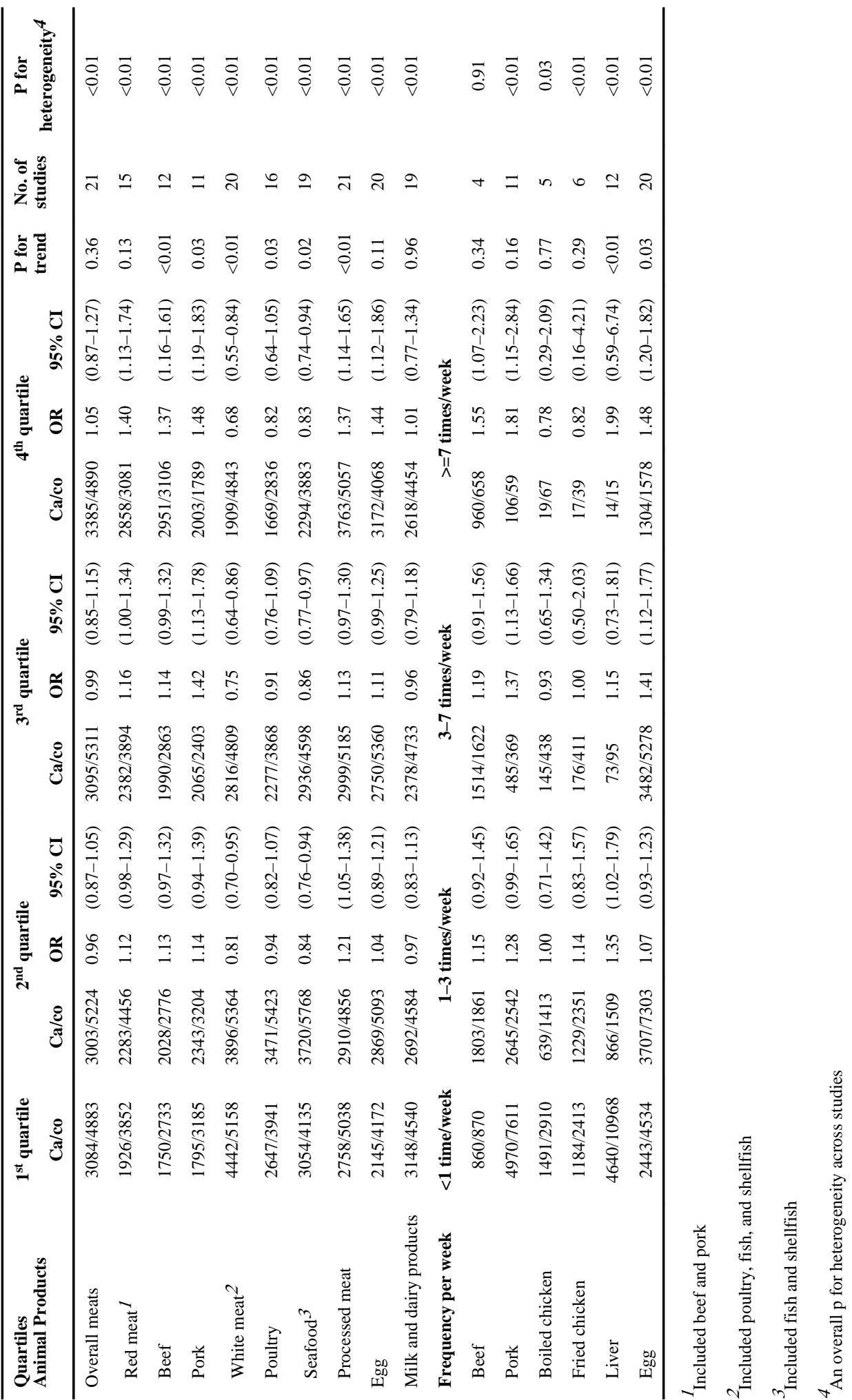


Table 6

Odds ratios (OR) and $95 \%$ confidence intervals (CI) for dietary pattern scores ${ }^{1}$ and head and neck cancer risks

\begin{tabular}{rrrrr}
\hline Scores & Cases & Controls & OR $^{2}$ & 95\% CI \\
\hline 0 & 466 & 325 & 1.00 & \\
1 & 858 & 754 & 0.94 & $(0.74-1.18)$ \\
2 & 1435 & 1506 & 0.87 & $(0.70-1.08)$ \\
3 & 1866 & 2423 & 0.72 & $(0.58-0.88)$ \\
4 & 1535 & 2557 & 0.63 & $(0.49-0.82)$ \\
5 & 1377 & 2570 & 0.60 & $(0.39-0.91)$ \\
6 & 1051 & 2332 & 0.54 & $(0.37-0.78)$ \\
7 & 482 & 1590 & 0.42 & $(0.26-0.67)$ \\
8 & 258 & 895 & 0.41 & $(0.27-0.63)$ \\
9 & 102 & 401 & 0.34 & $(0.24-0.49)$ \\
Every 1 score increment & & & 0.90 & $(0.84-0.97)$ \\
p trend & & & 0.01 & \\
\hline
\end{tabular}

1 Include Aviano, Italian Multicenter, Switzerland, Seattle, Los Angeles, Puerto Rico, South America, Boston, US Multicenter, MSKCC, SeattleLEO studies, Western Europe, and Japan studies. The higher scores indicate higher fruit and vegetable and lower red meat consumption.

2 The ORs were adjusted for age, sex, race, center, education level, packyears of cigarette smoking, duration of cigar smoking, duration of pipe smoking, intensity of alcohol drinking, and weight 
Table 7

Odds ratios (OR) and 95\% confidence intervals (CI) for selected food groups and head and neck cancer risks among never smokers and light drinkers $(<=3$ drinks/day)

\begin{tabular}{|c|c|c|c|c|}
\hline & Case & Control & OR & $95 \% \mathrm{CI}$ \\
\hline \multicolumn{5}{|c|}{ Overall Vegetable } \\
\hline 1st quartile & 260 & 1425 & 1.00 & \\
\hline 2nd quartile & 246 & 1618 & 0.84 & $(0.67-1.06)$ \\
\hline 3rd quartile & 233 & 1572 & 0.89 & $(0.71-1.12)$ \\
\hline 4thquartile & 276 & 1832 & 0.85 & $(0.60-1.19)$ \\
\hline $\mathrm{p}$ for trend & & & 0.15 & \\
\hline \multicolumn{5}{|c|}{ Overall Fruits } \\
\hline 1st quartile & 255 & 1180 & 1.00 & \\
\hline 2nd quartile & 243 & 1512 & 0.76 & $(0.59-0.95)$ \\
\hline 3rd quartile & 247 & 1837 & 0.66 & $(0.47-0.94)$ \\
\hline 4thquartile & 240 & 1776 & 0.66 & $(0.48-0.92)$ \\
\hline $\mathrm{p}$ for trend & & & 0.27 & \\
\hline \multicolumn{5}{|l|}{ Red meat } \\
\hline 1st quartile & 181 & 1257 & 1.00 & \\
\hline 2nd quartile & 194 & 1466 & 0.94 & $(0.72-1.23)$ \\
\hline 3rd quartile & 190 & 1187 & 1.26 & $(0.89-1.77)$ \\
\hline 4thquartile & 164 & 794 & 1.55 & $(1.15-2.10)$ \\
\hline $\mathrm{p}$ for trend & & & 0.19 & \\
\hline \multicolumn{5}{|l|}{ White meat } \\
\hline 1st quartile & 277 & 1398 & 1.00 & \\
\hline 2nd quartile & 290 & 1559 & 0.85 & $(0.59-1.24)$ \\
\hline 3rd quartile & 237 & 1514 & 0.70 & $(0.54-0.90)$ \\
\hline 4thquartile & 226 & 1705 & 0.62 & $(0.35-1.12)$ \\
\hline $\mathrm{p}$ for trend & & & 0.09 & \\
\hline \multicolumn{5}{|c|}{ Processed meat } \\
\hline 1st quartile & 290 & 1848 & 1.00 & \\
\hline 2nd quartile & 264 & 1618 & 1.02 & $(0.79-1.31)$ \\
\hline 3rd quartile & 220 & 1558 & 0.34 & $(0.04-2.91)$ \\
\hline 4thquartile & 183 & 1286 & 1.12 & $(0.90-1.39)$ \\
\hline $\mathrm{p}$ for trend & & & 0.62 & \\
\hline \multicolumn{5}{|l|}{ Scores } \\
\hline $0-2$ & 110 & 556 & 1.00 & \\
\hline $3-4$ & 206 & 1256 & 0.77 & $(0.56-1.06)$ \\
\hline $5-6$ & 197 & 1486 & 0.64 & $(0.43-0.95)$ \\
\hline $7-9$ & 115 & 1016 & 0.48 & $(0.32-0.74)$ \\
\hline $\mathrm{p}$ for trend & & & 0.04 & \\
\hline
\end{tabular}

